Servier, GSK, Merck Serono, Sergio Paira: None declared, Romina Calvo: None declared, Alberto Ortiz: None declared, Rodolfo Perez Alamino Speakers bureau: Pfizer, Abbvie, Amgen, Bristol-Myers-Squibb, Lilly, Janssen, Novartis, Hernan Maldonado Ficco Speakers bureau: Pfizer, Abbvie, Jansen, Novartis, Bago, Bristol, Eli Lilly., Consultant of: Pfizer, Abbvie, Novartis, Jansen, Bago, Eli Lilly., Gustavo Citera Speakers bureau: Abbvie, BMS, Lilly, Jansen, Gema, Pfizer, Roche, Grant/research support from: Pfizer

DOI: 10.1136/annrheumdis-2021-eular.1399

\section{AB0215 1 COMPARISON BETWEEN RITUXIMAB ORIGINATOR THERAPY AND ITS BIOSIMILAR IN THE INCIDENCE OF LATE-ONSET NEUTROPENIA IN ADULT PATIENTS WITH RHEUMATOID ARTHRITIS AND OTHER AUTOIMMUNE DISEASES}

M. M. Ahmad ${ }^{1}$, E. Mcrorie ${ }^{1}$. 'Western General Hospital, Rheumatology, Edinburgh, United Kingdom

Background: Late-onset neutropenia (LON) occurs when the absolute neutrophil count drops below $1.5 \times 10(9) / L$ four weeks after Rituximab infusion. ${ }^{1}$ It is a condition recognised more in haematological malignancy patients treated with Rituximab with a reported prevalence of $8 \%$ or higher. ${ }^{2}$ LON was reported in $6.5 \%$ of rheumatological patients ${ }^{1}$, while a French registry found a prevalence of $1.3 \%$ in rheumatoid arthritis patients. ${ }^{3}$

Almost all patients receiving Rituximab originator therapy at our Rheumatology department were switched to its biosimilar starting from November 2017. Our haematology team observed LON cases in their patients after this period.

Objectives: We wanted to establish whether there is increased LON occurrence with the biosimilar than the originator therapy, requiring specific monitoring.

Methods: This is a cross-sectional retrospective review of 12 months period before and after switching to the biosimilar of all patients who received Rituximab for the first time. We reviewed the patients' blood monitoring for up to 12 months after receiving Rituximab. We used a proforma to collect the age, sex, diagnosis, date of the first infusion, use of other DMARDs, LON occurrence within 12 months after the infusion and neutropenia within the 12 months before it in addition to the frequency of the blood monitoring after the infusion.

Results: For the originator, between 1/1/2016 and 31/12/2016, 142 patients received Rituximab, 47 (33.09\%) of them were given the treatment for the first time. Their median age was 62 years, 28 (59.5\%) were females. The most common diagnosis was rheumatoid arthritis $38(80.8 \%)$, and $35(74.4 \%)$ patients were on other disease-modifying agents (DMARDs). Two patients $(4.2 \%)$ developed LON. In both patients, this occurred during admission for septic arthritis whilst on antibiotics, and both had Grade $2: \geq 1,000-<1,500$ / mm3 neutropenia.

For the Biosimilar cohort, between 1/4/2019 and 31/3/2020, 161 patients received Rituximab, $36(22.3 \%)$ of them were given the treatment for the first time. Their median age was 59 years, $27(75 \%)$ of them were females. The most common diagnosis was rheumatoid arthritis $25(69.4 \%)$, and $26(72.2 \%)$ were on other DMARDs. One patient $(2.77 \%)$ developed grade 2 LON one month after Rituximab. Another patient with known autoimmune neutropenia was excluded. In all the Three patients with LON in both groups, neutrophil count recovered in less than a month, and they had normal IgG before the infusion.

The frequency of blood monitoring after Rituximab infusion was done 1-3 monthly in $32(68 \%)$ patients and $23(63.8 \%)$ patients in the originator and biosimilar groups, respectively.

Four $(8.5 \%)$ patients and three (8.3\%) patients in the originator and biosimilar groups respectively had a frequency of blood monitoring done less than six-monthly.

Conclusion: In our patients' cohort, LON incidence following switching to the Rituximab biosimilar was not higher than the originator therapy.

REFERENCES:

[1] Monaco, W. E., Jones, J. D. \& Rigby, W. F. C. Rituximab associated late-onset neutropenia-a rheumatology case series and review of the literature. Clin Rheumatol 35, 2457-2462 (2016).

[2] Dunleavy, K., Tay, K. \& Wilson, W. H. Rituximab-Associated Neutropenia. Seminars in Hematology 47, 180-186 (2010).

[3] Salmon, J. H. et al. Late-onset neutropenia after treatment with Rituximab for rheumatoid arthritis and other autoimmune diseases: data from the Autolmmunity and Rituximab registry. RMD Open 1, e000034 (2015).

Acknowledgements: The authors would like to thank pharmacist Christine Hay for her help in providing the Rituximab databases.

Disclosure of Interests: Mostafa Meshaal Ahmad: None declared, Euan McRorie Speakers bureau: I have spoken at meetings sponsored by Roche several years ago, Consultant of: I have sat on advisory boards for Roche several years ago., Grant/research support from: I was the local investigator for the ORBIT study, published in the Lancet in 2016.

DOI: 10.1136/annrheumdis-2021-eular.1544

\section{AB0216 LONG-TERM RESULTS OF T2T THERAPY INITIATED AT THE ONSET OF RHEUMATOID ARTHRITIS (DATA FROM OREL REGISTRY)}

V. Rybakova ${ }^{1}$, A. Avdeeva ${ }^{2}$, Y. Olyunin ${ }^{2}$, E. Nasonov ${ }^{3,4} .{ }^{1}$ V.A. Nasonova Research Institute of Rheumatology, Outpatient Department, Moscow, Russian Federation; ${ }^{2}$ V.A. Nasonova Research Institute of Rheumatology, Laboratory of Early Arthritis, Moscow, Russian Federation; ${ }^{3}$ V.A. Nasonova Research Institute of Rheumatology, Scientific S, Moscow Russian Federation; ${ }^{4}$ I.M. Sechenov First Moscow State Medical University, Ministry of Health of Russia (Sechenov University), Department of Therapy and Occupational Diseases, Moscow, Russian Federation

Background: Current guidelines for the treatment of rheumatoid arthritis (RA) recommend early administration of methotrexate (MTX) and addition of a biologic if MTX monotherapy does not provide remission or low activity of the disease. Efficacy of this strategy in real clinical practice was assessed using data from the Russian RA registry OREL.

Objectives: To analyze long-term results of intensive treatment initiated at RA onset in real clinical practice.

Methods: 141 RA patients with disease duration less than 3 years $(29$ men, 112 women) were included. 112 were positive for rheumatoid factor and $119-$ for anti-cyclic citrullinated peptide antibody. Subcutaneous MTX was initiated at $10-15 \mathrm{mg}$ per week with further dose escalation up to $20-30 \mathrm{mg}$ per week. Therapy was adjusted every 3 months. If MTX monotherapy did not allow to achieve treatment target of remission or low disease activity, biologics were added.

Results: Median DAS 28 at baseline was $5,31[4,79 ; 6,14]$. Initiation of treatment resulted in steady decrease of disease activity $(p<0.05$, table1). After 1 year of follow-up $33.8 \%$ of patients received MTX monotherapy, 33.8\% - MTX in combination with tumor necrosis factor alpha inhibitors, $22.0 \%-$ MTX +abatacept, $0.55 \%-$ MTX + tocilizumab, $0.47 \%-$ MTX + rituximab. Low disease activity was achieved in $16.3 \%$ patients, and remission - in $45.8 \%$. After 6 years median age of patients was $58[49 ; 66]$ years, disease duration - $84[79$ 89] months, low disease activity was documented in $21.3 \%$, and remission - in $7.8 \%$ of cases (fig. 1). $7 \%$ of patients were able to maintain remission without any treatment. Biologics were discontinued in 15 patients after achieving remission or low disease activity, and synthetic DMARDs - in 5 patients having remission.

Conclusion: Intensive therapy initiated at RA onset demonstrates high effectiveness, allowing $61.5 \%$ of patients to achieve low disease activity or remission within 12 months, and to maintain these results after 6 years of treatment in $29.2 \%$. Adherence to this strategy allowed to discontinue biologics in 15 patients and synthetic DMARDs in 5 patients after achieving treatment target.

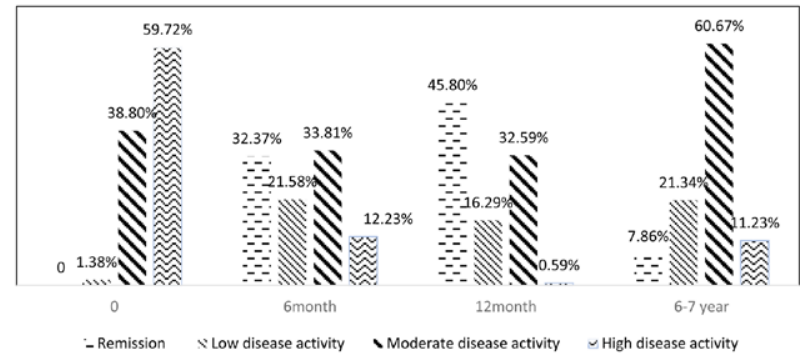

Figure 1. Changes of the disease activity during follow-up

Table 1. Changes of the main inflammatory activity measures, Me $\left[25^{\text {th }}\right.$; $75^{\text {th }}$ percentile]

\begin{tabular}{lccc}
\hline Parametres & $\mathbf{0}$ & $\mathbf{1 2}$ months & 6 years \\
\hline DAS28 & $5,31[4,79 ; 6,14]$ & $2,85[2 ; 3,90]^{*}$ & $4,008[3,4 ; 4,59]^{*}$ \\
SDAl & $28,27[18,79 ; 40,73]$ & $5,67[2 ; 11,98]^{*}$ & $15,06[9,32 ; 21]^{*}$ \\
CDAI & $25[17 ; 36]$ & $5[1,7 ; 11]^{*}$ & $15[9 ; 21]^{*}$ \\
ESR (mm/hr) & $32[19 ; 50]$ & $16[8 ; 30]^{*}$ & $16[10 ; 25]^{*}$ \\
CRP (mg/l) & $26,55[6,4 ; 45,30]$ & $3,85[1,5 ; 11,3]^{*}$ & $2,2[0,9 ; 4,9]^{*}$
\end{tabular}

${ }^{*} \mathrm{p}<0.05$ in all cases.

Disclosure of Interests: None declared

DOI: 10.1136/annrheumdis-2021-eular.1552 